\title{
Os processos de gestão de pessoas a partir da inclusão de pessoas com deficiência
}

O objetivo deste estudo é analisar a satisfação dos colaboradores com deficiência e a percepção de seus colegas de trabalho quanto as práticas de gestão de pessoas, frente a inclusão e a lei de cotas, em uma Cooperativa de Saúde da região noroeste do estado do Rio Grande do Sul. Quanto ao método, realizou-se uma pesquisa com abordagem qualitativa e quantitativa, sendo os dados obtidos através de aplicação de questionário estruturado a 25 profissionais enquadrados como pessoas com deficiência (PCDs) e 33 colegas de trabalho sem deficiência que atuam em áreas onde as PCDs estão inseridas. Para análise dos dados se realizou uma triangulação entre os dados obtidos com as PCDs e colegas de trabalho a partir de cinco dos seis processos de gestão de pessoas definidos pelo autor Chiavenato (2010): agregar, aplicar, recompensar, desenvolver e manter. O estudo evidenciou que os processos de gestão de pessoas na organização em estudo promovem a efetiva inclusão de PCDs, pois os profissionais com deficiência, em sua maioria, sentem-se satisfeitos, sendo que a maioria dos seus colegas também possui essa percepção, entendendo que a inclusão ocorre não apenas para o cumprimento da lei de cotas, pois há o compromisso da organização com o desenvolvimento das pessoas com deficiência enquanto sujeitos e cidadãos, sendo the devolvida a dignidade outrora perdida em meio à discriminação e segregação praticadas pela sociedade.

Palavras-chave: Gestão de Pessoas; Inclusão; Pessoas com Deficiência; PCDs; Lei de Cotas.

\section{Management of people processes bythe inclusion of people with disabilities}

The objective of this study is to analyze the satisfaction of employees with disabilities and the perception of their work colleagues regarding the practices of people management before inclusion and the quota law in a Health Cooperative in the northwestern region of Rio Grande do Sul state. As the employed method, a qualitative and quantitative research was carried out. The data were obtained through the application of a structured questionnaire to 25 professionals classified as people with disabilities (PWD) and 33 non-disabled working colleagues who work in areas where the PWD are inserted. To analyze the data, a triangulation between the data obtained with the PWD and co-workers was carried out from five processes of people management, as defined by the author Chiavenato (2010): aggregate, apply, reward, develop and maintain. The study pointed out that the processes of people management in the organization studied promote the effective inclusion of PWD, since professionals with disabilities, for the most part, feel satisfied, and most of their colleagues also have this perception, understanding that the inclusion occurs not only for compliance with the quota law, because there is the commitment of the organization with the development of people with disabilities as subjects and citizens, being restored the dignity once lost on the discrimination and segregation practiced by society.

Keywords: People Management; Inclusion; People with Disabilities; PWD; Law of Quotas.

Topic: Recursos Humanos

Reviewed anonymously in the process of blind peer.

Luis Fernando Irgang dos Santos

Halmstad University, Suécia

http://lattes.cnpq.br/0796218364588427

luis.irgang@hotmail.com

Adriane Fabricio

Universidade Federal de Santa Maria, Brasil

http://lattes.cnpq.br/9275057052526069

adriane.fabricio@unijui.edu.br

\section{Liane Beatriz Rotili}

Universidade Regional do Noroeste do Estado do Rio Grande do Sul,

Brasil

http://lattes.cnpq.br/5588975635262698

http://orcid.org/0000-0003-4425-5892

liane.rotili@hotmail.com
Received: 07/10/2017

Approved: 06/12/2017
Daniel Knebel Baggio

Universidad de Zaragoza, Espanha

http://lattes.cnpq.br/4185695953545371

danibaggio@gmail.com
Referencing this:

SANTOS, L. F. I.; FABRICIO, A.; ROTILI, L. B.; BAGGIO, D. B.. Os processos de gestão de pessoas a partir da inclusão de pessoas com deficiência. Revista Brasileira de Administração Científica, v.8, n.3, p.38-58, 2017. DOI: http://doi.org/10.6008/SPC2179$\underline{684 X .2017 .003 .0004}$ 


\section{INTRODUÇÃO}

Ao longo da história da humanidade, as pessoas com deficiência sempre foram alvo de discriminação, sendo tratadas como uma ameaça social. Segundo Silva (1987), na Pré-história a maioria dos povos nômades sacrificava ou abandonava os membros mais vulneráveis para que não prejudicassem as longas jornadas percorridas em busca de alimento e abrigo. Sassaki (1997) destaca que crenças antigas, registradas até mesmo em livros da Bíblia, manifestam eventos que comprovam a discriminação contra pessoas e animais imperfeitos de forma aberta nas próprias leis do povo Hebreu.

De acordo com Gugel (2007), na Idade Média havia uma espécie de mercado negro, onde as crianças que nasciam com algum tipo de deficiência eram vendidas para mais tarde servirem como bobos da corte e entreter a nobreza. Ainda segundo a autora, foi a partir do período conhecido como Renascimento que as deficiências passaram da abordagem mística para a científica, onde foram desenvolvidos conceitos que se reconfiguram até os dias atuais.

No Brasil, a partir da década de 1920 foram criadas organizações como o Instituto Pestalozzi e mais tarde e a Associação de Pais e Amigos dos Excepcionais (APAE), que proporcionaram espaços de convívio e contribuíram para forjar uma identidade das pessoas com deficiência, bem como sua composição enquanto grupo social (BRASIL, 2010).

A Constituição Federal do Brasil de 1988 (BRASIL, 1988), conhecida como Constituição Cidadã, foi um importante marco que colocou o Estado como responsável pela garantia de igualdade e justiça às pessoas com deficiência, propondo os primeiros dispositivos legais em áreas como educação, trabalho, assistência social e acessibilidade física, de forma a garantir a inclusão social das pessoas com deficiência (PCDs).

De acordo com o Instituto Brasileiro de Geografia e Estatística (IBGE, 2010) estima-se que cerca de 45,6 milhões de brasileiros possuem algum tipo de deficiência, o que representa quase 1/4 da população. Segundo os dados da Relação Anual de Informações Sociais (Rais), em 2014 o Brasil registrava a marca de 49.571.510 vínculos empregatícios formais. Destes, o número de vagas preenchidas por PCDs era de apenas 381,3 mil, correspondendo a 0,7\% do total de vínculos (BRASIL, 2016).

Segundo o Ministério do Trabalho e Emprego (MTE), a Lei de Cotas, regulamentada pela Lei no 8.213, de 24 de julho de 1991, implantada em 1999 pelo Decreto no 3.298, é atualmente um dos mais importantes mecanismos de inclusão social das pessoas com deficiência e impôs novos desafios aos gestores, que a partir de então precisam reorganizar os referenciais estratégicos das organizações e aplicar práticas de gestão que promovam a inclusão de profissionais com deficiência em seu quadro de colaboradores.

Diante deste contexto, a cooperativa de saúde em estudo se desafiou a estruturar um plano de ação para documentar e padronizar as práticas inclusivas de gestão de pessoas, não somente em atendimento à lei de cotas, mas, sobretudo, apostando na inclusão como um importante valor inerente aos princípios do cooperativismo. A partir de 2014 foi criado o Programa Pertencer, em que a cooperativa passou a tratar a inclusão como política de gestão de pessoas, tendo, inclusive, recebido o prêmio Top Ser Humano 2015 como forma de reconhecimento à cultura da inclusão vivenciada na instituição. 
Frente à realidade apresentada, este estudo teve como objetivo analisar a satisfação dos colaboradores com deficiência e a percepção de seus colegas de trabalho quanto as práticas de gestão de pessoas, frente a inclusão e a lei de cotas, em uma Cooperativa de Saúde da região noroeste do estado do Rio Grande do Sul, a partir de cinco processos de gestão de pessoas definidos pelo autor Chiavenato (2010). O presente artigo está estruturado em quatro partes: inicialmente é apresentada uma fundamentação teórica sobre pessoas com deficiência e Lei das Cotas, seguida de práticas de gestão de pessoas. Na sequência é apresentada a metodologia, a análise dos resultados e por fim as considerações finais do estudo.

\section{REVISÃO TEÓRICA}

\section{Pessoa com deficiência (PCD) e Lei das Cotas}

Na literatura atual, muito se tem discutido sobre a temática da deficiência e o papel do Estado e da sociedade como um todo em relação às pessoas com deficiência. No contexto organizacional, porém, percebe-se que há uma carência de estudos e relatos de experiências efetivas de inclusão. Para que as pessoas com deficiência sejam de fato incluídas no mercado de trabalho, verifica-se a importância do entendimento do conceito de pessoas com deficiência e os dispositivos legais que as amparam. Conforme a Declaração dos Direitos das Pessoas Deficientes, aprovada pela Assembleia Geral da Organização das Nações Unidas em 1975, primeira página 'o termo 'pessoa deficiente' refere-se a qualquer pessoa incapaz de assegurar por si mesma, total ou parcialmente, as necessidades de uma vida individual ou social normal, em decorrência de uma deficiência, congênita ou não, em suas capacidades físicas ou mentais'.

O Decreto 6.949/09 que trata sobre a Convenção Internacional Sobre os Direitos das Pessoas com Deficiência reconhece que deficiência é um conceito em evolução e que resulta da interação entre pessoas com deficiência e as barreiras devidas às atitudes e ao ambiente que impedem a plena participação dessas pessoas na sociedade em igualdade de oportunidades com as demais pessoas. Segundo Sassaki (2005), a ONU aprovou em 2006, através da Convenção Internacional para Proteção e Promoção dos Direitos e da Dignidade das Pessoas com Deficiência, a internacionalização da terminologia "pessoa com deficiência", assim reivindicado por ONGs de vários países. Acredita-se que esta é a denominação ideal para evitar neologismos que tentam diluir as diferenças e mostrar com dignidade a realidade da pessoa com deficiência.

A condição de ter uma deficiência faz parte da pessoa e esta pessoa não porta sua deficiência. Ela tem uma deficiência. Tanto o verbo 'portar' como o substantivo ou o adjetivo 'portadora' não se aplicam a uma condição inata ou adquirida que faz parte da pessoa. Por exemplo, não dizemos e nem escrevemos que uma certa pessoa é portadora de olhos verdes ou pele morena. Uma pessoa só porta algo que ela possa não portar, deliberada ou casualmente. Por exemplo, uma pessoa pode portar um guarda-chuva se houver necessidade e deixá-lo em algum lugar por esquecimento ou por assim decidir. Não se pode fazer isto com uma deficiência, é claro. (SASSAKI, 2003)

A Constituição Federal de 1988 traz, em seu artigo 227, Inciso II, que o Estado deve promover a criação de programas de prevenção e atendimento especializado para as pessoas com deficiência, bem como de integração social, mediante treinamento para o trabalho e a convivência, com a eliminação de preconceitos e obstáculos arquitetônicos. 
De acordo com a Secretaria de Inspeção do Trabalho - SIT, a inclusão social é a palavra-chave a nortear todo o sistema de proteção institucional da pessoa com deficiência no Brasil. Implica na ideia de que há um débito social secular a ser resgatado em face das pessoas com deficiência. A Lei no 7.853, de 24 de outubro de 1989, traça a diretriz central a respeito do direito da PCD ao trabalho, estabelecendo que cabe ao poder público e a seus órgãos assegurar às PCDs o pleno exercício de seus direitos básicos, o que contempla o direito ao trabalho.

Quanto à inclusão da PCD no mercado de trabalho, a Constituição Federal de 1988 traz em seu artigo 70, inciso XXXI, a 'proibição de qualquer discriminação no tocante a salário e critérios de admissão do trabalhador portador [sic] de deficiência'. A Lei no 8.213, de 24 de julho de 1991, também conhecida como 'Lei de Cotas' implantada em 1999 pelo Decreto 3.298, é atualmente um dos mais importantes mecanismos de inclusão social das pessoas com deficiência. Esta lei estabelece a reserva de vagas de emprego para pessoas com deficiência (habilitadas) ou para aquelas que sofreram acidentes de trabalho, beneficiárias da Previdência Social (reabilitadas). No Artigo 93ํ, da Lei no 8.213, de 24 de julho de 1991, são determinadas as cotas mínimas de PCDs para empresas:

A empresa com 100 (cem) ou mais empregados está obrigada a preencher de $2 \%$ (dois por cento) a $5 \%$ (cinco por cento) dos seus cargos com beneficiários reabilitados ou pessoas portadoras [sic] de deficiência, habilitadas, na seguinte proporção:

I - até 200 empregados - 2\%;

II - de 201 a 500 - 3\%;

III - de 501 a 1.000 - 4\%;

IV - de 1.001 em diante - 5\%.

Para o cumprimento da chamada lei de cotas, o Decreto no 3.298/99, art. 31 oficializou o termo "pessoa reabilitada". Entende-se por reabilitada a pessoa que passou por processo orientado a possibilitar que adquira, a partir da identificação de suas potencialidades laborativas, o nível suficiente de desenvolvimento profissional para reingresso no mercado de trabalho e participação na vida comunitária.

Visando garantir a permanência das pessoas com deficiência nos postos de trabalho, a mesma lei prevê multa aplicável em caso de dispensa de empregado com deficiência, sem que tenha havido a contratação antecedente de substituto em condições semelhantes. Caso uma empresa deseje dispensas um empregado com deficiência ou reabilitado, deverá antes providenciar a contratação de outra pessoa com deficiência (BRASIL, 1991).

De acordo com a Portaria MPS no 142, de 11 de abril de 2007, foram estabelecidas as penalidades à empresa que descumprir o art. 93 da Lei $n$ o 8.213/91, conforme estabelece seu art. 10, $\mathrm{V}$, com multas administrativas que podem chegar a quase $\mathrm{R} \$ 120.000,00$. Mesmo com a promulgação da lei de cotas, dados do MTE (2016) apontam que cerca de 30\% das contratações de pessoas com deficiência ainda ocorrem por iniciativa de empresas que não se enquadram na lei de cotas, ou seja, com quadro de colaboradores inferior a 100 pessoas. 


\section{Processos de Gestão de Pessoas}

A gestão de pessoas vem desenvolvendo um papel de destaque junto às organizações, notada a sua importância para o sucesso dos negócios. A partir deste contexto, na medida em que acompanha a evolução da sociedade, a gestão de pessoas se torna cada vez mais complexa. Por estas razões, Chiavenato (2010) sugere um modelo de classificação das atividades de GP que as subdivide em seis processos: processo de agregar, aplicar, recompensar, desenvolver, manter e monitorar pessoas, sendo que, para este estudo são considerados o estudo das práticas dos cinco primeiros processos.

O primeiro processo é o de agregar pessoas, que consiste em prover a organização de novos funcionários, seja para substituição de outros ou em virtude da expansão do negócio e aumento do quadro funcional da organização. Este processo inclui as práticas de recrutamento e seleção de pessoas. O recrutamento pode ser definido como o processo que engloba todos os procedimentos para atrair candidatos potencialmente qualificados ao preenchimento de um determinado cargo na organização, suprindo-o com os conhecimentos, habilidades e comportamentos que auxiliem a organização a alcançar seus objetivos e manter sua competitividade (MARRAS, 2007).

Conforme sugere Gil (2007), deve ser realizado com base na descrição da função a ser preenchida e a partir de então, o selecionador poderá determinar onde poderá encontrar os tipos de candidatos potencialmente qualificados e capazes de ocuparem cargos na organização. Em relação a sua aplicação, o recrutamento pode ser interno, quando a organização busca preencher vagas através do remanejamento de seus funcionários de forma vertical ou horizontal; ou externo, quando a busca por candidatos ocorre fora do ambiente da organização. Para ser eficaz, o recrutamento deve atrair um contingente de candidatos suficiente para a realização do processo de seleção (GIL, 2010).

A partir do momento em que um ou mais candidatos manifestem interesse pela vaga, faz-se necessário que a organização proceda com técnicas de seleção para buscar, dentre os vários candidatos recrutados, os mais adequados aos cargos disponíveis. Dentre os diversos métodos de seleção existentes, recomenda-se que sejam utilizados nos estágios iniciais da seleção, segundo Gil (2007) e Milkovich et al. (2000), as análises curriculares, testes escritos, testes práticos, testes psicológicos, entrevistas e dinâmicas de grupo.

O segundo processo é o de agregar pessoas que, de acordo com Chiavenato (2010) “[...] envolvem os primeiros passos na integração dos novos membros na organização, o desenho do cargo a ser desempenhado e a avaliação de desempenho no cargo". A orientação é a forma com que as pessoas são posicionadas no ambiente organizacional, o modo como devem conduzir suas atividades e esforços e a maneira como são definidos os comportamentos e ações. Nesse contexto, é necessário que a orientação oferecida ao novo funcionário esteja alinhada aos valores, normas, hábitos, atitudes e expectativas da organização, ou seja, pautada na cultura da organização (CHIAVENATO, 2010).

A descrição de cargos é um processo que consiste em enumerar tarefas ou atribuições que compõem o cargo e que o tornam distintos de todos os demais existentes na organização. Para Chiavenato (2010), o cargo é uma composição de todas as atividades desempenhadas por uma pessoa que podem ser alocadas 
em uma posição formal no organograma da organização. Os cargos servem como base para a aplicação das pessoas nas tarefas organizacionais, constituindo seus deveres e as responsabilidades no exercício de seu trabalho, e com base nisso, tem-se a avaliação de desempenho para ponderar o funcionamento das atividades.

A prática da avaliação de desempenho é utilizada por qualquer organização que tenha empregados, mesmo às vezes a realizando de modo informal (DESSLER, 2003). O desempenho das pessoas passa a ser medido pelo valor efetivo de sua contribuição ao patrimônio de competências da organização, que permitem a ela manter suas vantagens competitivas ao longo do tempo (DUTRA, 2004). Um desempenho superior significa que o colaborador é capaz de utilizar seu repertório individual de conhecimentos, habilidades e atitudes para aprimorar e transformar a organização (FLEURY et al., 2004).

O terceiro processo é o de recompensar pessoas que corresponde ao elemento fundamental da relação de trabalho estabelecida entre empregador e empregado. As pessoas estarão dispostas a dedicar sua força de trabalho à organização a partir do momento em que são devidamente reconhecidas por seu trabalho e esforço através de uma remuneração, composta pela remuneração básica, incentivos salariais e benefícios (CHIAVENATO, 2010). Para Milkovich et al. (2000), em um sistema de remuneração eficaz, as políticas de pagamento são escolhidas para ajudar no cumprimento dos objetivos do sistema.

O processo de desenvolvimento está diretamente ligado à educação. Segundo Chiavenato (2010), desenvolver pessoas é "[...] dar-Ihes a formação básica para que aprendam novas atitudes, soluções, ideias, conceitos e que modifiquem seus hábitos e comportamentos e se tornem mais eficazes naquilo que fazem". O autor destaca que os processos de desenvolvimento envolvem três estratos, que se superpõem: o treinamento, o desenvolvimento de pessoas e o desenvolvimento organizacional.

O processo de treinamento refere-se ao conjunto de experiências de aprendizagem centradas na determinação de ações pontuais para a melhoria da capacidade das pessoas (MARRAS, 2007). 0 treinamento é, portanto, um processo focado no curto prazo, levando em conta a posição atual da organização (GIL, 2007). O processo de desenvolvimento refere-se ao conjunto de experiências de aprendizagem não necessariamente relacionadas aos cargos que as pessoas ocupam atualmente, mas que proporcionam oportunidades para o crescimento profissional (GIL, 2007).

Esse conceito está ligado à capacidade da empresa em criar as condições de aprendizagem necessárias para que os funcionários modifiquem comportamentos, desenvolvam habilidades valorizadas pela organização e aprimorarem seus conhecimentos, contribuindo efetivamente para o aprimoramento das capacidades organizacionais (DESSLER, 2003).

O quinto processo consiste em manter pessoas. Chiavenato (2010) comenta que este "[...] existe para manter os participantes satisfeitos e motivados e para assegurar-Ihes condições físicas, psicológicas e sociais de permanecer na organização, obter seu compromisso e de vestir a sua camisa". As organizações precisam das pessoas suficientemente motivadas a trabalharem em prol do alcance dos objetivos organizacionais. Empregados motivados para realizar seu trabalho tendem a proporcionar melhores resultados às 
organizações, o que significa que a motivação, seja individual ou em grupo, é a principal impulsionadora da produtividade nas empresas (GIL, 2007).

Para que seja assegurada a qualidade de vida na organização, há que se ter um conjunto de cuidados especiais, entre os quais sobressaem os estilos de gerência, as relações com empregados e os programas de higiene e segurança do trabalho (CHIAVENATO, 2010). Para Chiavenato (2010) "a higiene do trabalho está relacionada com as condições ambientais de trabalho que assegurem a saúde física e mental e com as condições de saúde e bem-estar das pessoas".

A qualidade de vida no trabalho envolve tanto aspectos físicos e ambientais, como os aspectos psicológicos do local de trabalho. Segundo Chiavenato (2010), a má qualidade de vida no trabalho pode conduzir à alienação do empregado e à insatisfação, à má vontade, ao declínio da produtividade, ao absenteísmo, rotatividade, roubo, sabotagem, etc. O conceito de qualidade de vida no trabalho implica profundo respeito pelas pessoas e que para alcançar níveis elevados de qualidade e produtividade, as organizações precisam de pessoas motivadas, que participem ativamente nos trabalhos que executam e que sejam adequadamente recompensadas pelas suas contribuições.

\section{METODOLOGIA}

Visando responder ao objetivo deste estudo, empreendeu-se um estudo com abordagem qualitativa e quantitativa, sendo os dados obtidos através de aplicação de questionário semiestruturado aos quatro gestores de $\mathrm{RH}$, bem como questionário estruturado a 25 profissionais com deficiência e 33 colegas de trabalho sem deficiência que atuam em áreas onde as PCDs estão inseridas. Para análise dos dados se realizou uma triangulação entre os dados obtidos com os gestores de RH, as PCDs, colegas de trabalho e os cinco processos e suas respectivas práticas de gestão de pessoas conforme o modelo definido pelo autor Chiavenato (2010), agregar, aplicar, recompensar, desenvolver e manter.

Inicialmente foi realizada pesquisa bibliográfica por meio da seleção de estudos de relevância na temática. Esta fase teve como intuito proporcionar sustentação a discussão do fenômeno estudado. Optouse assim, por estruturar um questionário baseado nos processos de gestão de pessoas definidos por Chiavenato (2010) adaptando a realidade da organização, baseando o foco do estudo nos cinco primeiros processos de gestão de pessoas e, suas respectivas práticas.

Após a definição dos critérios a serem levantados na coleta de dados, foi realizada uma entrevista semiestruturada com os quatro gestores de RH da organização com 26 questões, elaboradas a partir da lei de cotas e dos processos de gestão de pessoas definidos por Chiavenato (2010), visando identificar sua percepção quanto às práticas inclusivas de gestão de pessoas adotadas pela organização.

Posteriormente, a partir das considerações destes, foram elaborados e aplicados os demais questionários, compostos por 13 questões fechadas (com espaço para o registro da justificativa do participante) aos 25 dos 30 colaboradores com deficiência, e outros 33 questionários aplicados aos coordenadores e colaboradores de 17 setores diferentes, onde se encontram incluídos os profissionais com deficiência e reabilitados na organização, levando em conta sua disponibilidade e interesse em responder à 
pesquisa. É importante salientar que os questionários direcionados às PCDs, aos coordenadores e demais colaboradores foram elaborados com a mesma sequência de questões, sendo apenas adaptadas a linguagem e abordagem com o intuito de buscar identificar se há relação entre a percepção dos sujeitos da pesquisa.

Segundo as classificações de Beuren (2004), pode-se afirmar que os dados também foram analisados de forma descritiva, através do relato do comportamento das variáveis e da comparação com as características dos fenômenos da população. Salienta-se que, para o desenvolvimento de escalas sociais, foi adotada a Escala Likert de 5 níveis, onde escolhe-se 1 dentre os 5 enunciados que manifestam opinião ou atitude acerca do problema a ser estudado (GIL, 2008).

No caso do questionário aplicado às PCDs, é investigado o nível de satisfação com as práticas de gestão de pessoas adotadas pela cooperativa. Para os demais colaboradores, buscou-se saber a sua percepção em relação à efetividade destas mesmas práticas inclusivas de gestão de pessoas. Para a análise dos dados foi usado o software Microsoft Excel 2016 para obter a frequência das respostas, dando base a triangulação com os processos e práticas de gestão de pessoas, a partir da definição de Chiavenato (2010) em relação às $\mathrm{PCD}$.

\section{RESULTADOS E DISCUSSÃO}

A amostra do estudo foi composta por quatro gestores de $\mathrm{RH}, 25$ profissionais com deficiência e 33 colegas de trabalho sem deficiência que atuam em áreas onde as PCDs estão inseridas. Ressalta-se que, primeiramente, buscou-se apresentar a identificação do perfil da amostra e, em segundo momento, procurou-se analisar a percepção das PCDs e seus colegas de trabalho, referente aos cinco processos de gestão de pessoas.

De acordo com a pesquisa, verifica-se a predominância do gênero masculino, que representa $60 \%$ dos trabalhadores com algum tipo de deficiência que atuam na cooperativa. Entretanto, a diferença é relativamente pequena, o que demonstra que o fator gênero não é determinante para o preenchimento das vagas de PCDs na organização.

Em relação a faixa etária, $40 \%$ dos colaboradores são jovens com idade entre 21 e 30 anos, $36 \%$ se encontram na faixa dos 31 aos 40 anos e $16 \%$ possuem mais de 40 anos. No que se refere ao tempo de atuação, quase metade (44\%) das PCDs apresentam vínculo de trabalho de 1 a 2 anos e $28 \%$ trabalham há menos de 1 ano na organização, sendo que 16\% possuem entre 2 e 3 anos de trabalho, $8 \%$ com mais de 3 e menos de 4 anos e $4 \%$ com mais de 4 anos de trabalho. Em relação a distribuição das PCDs na organização, verifica-se que estas se encontram alocadas nos mais diversos setores, executando tanto funções de apoio (como higienização, telefonia, hotelaria, etc.) quanto funções técnicas e em cargos de chefia (enfermaria, farmácia, $\mathrm{CDI}$, etc.).

\section{Percepção das PCDs e colegas de trabalho}

De acordo com os estudos de Carvalho-Freitas (2009), para que uma organização promova a inclusão de PCDs de forma efetiva, faz-se necessário analisar 3 fatores: a sensibilização e percepção dos colaboradores 
e chefia quanto à inclusão de PCDs, a percepção e satisfação das PCDs quanto às adaptações e condições de trabalho oferecidas pela organização e, por fim, as práticas de RH desenvolvidas para garantir a inclusão, fator este que indica a percepção das pessoas em relação à adequação das práticas de seleção, treinamento, promoção e transferência, realizadas pela empresa, com vistas a inserir as pessoas com deficiência.

Com base nas afirmações de Carvalho-Freitas (2009), foi realizada uma entrevista semiestruturada com gestores de RH, a fim de apurar seu conhecimento em relação à lei de cotas, bem como identificar sua percepção em relação às práticas de gestão de pessoas desenvolvidas na organização para a inclusão de PCDs. Para verificar a satisfação das PCDs incluídas, foi aplicado um questionário com 13 questões, que permitiu ao respondente atribuir, numa escala de 1 a 5 , o seu nível de satisfação quanto às práticas de inclusão desenvolvidas pela organização. Da mesma forma, foi aplicado um questionário com 13 questões aos demais colaboradores e coordenadores de setor da organização, porém com uma abordagem que verificasse sua percepção quanto às mesmas práticas se, em sua opinião, promovem a efetiva inclusão de PCDs.

Nesta etapa são apresentados os resultados obtidos a partir da aplicação dos questionários e entrevistas, promovendo análises comparativas de cinco processos de gestão de pessoas (agregar, aplicar, recompensar, desenvolver e manter pessoas), a partir da percepção dos profissionais de RH, das PCDs e dos coordenadores de setor e demais colaboradores, relacionando estas informações com os dispositivos legais contemplados na lei de cotas.

\section{Processo de agregar pessoas}

O processo de agregar, também denominado como de provisão ou suprimento de pessoas, corresponde aos processos utilizados para incluir novos profissionais na organização através das atividades de recrutamento e seleção (SCHWARZ et al., 2006). A figura 1 representa o nível de satisfação das PCDs referente ao processo de agregar pessoas, considerando a divulgação das oportunidades de trabalho, a forma de disponibilização das vagas e o processo seletivo de profissionais com deficiência para sua incorporação na organização.

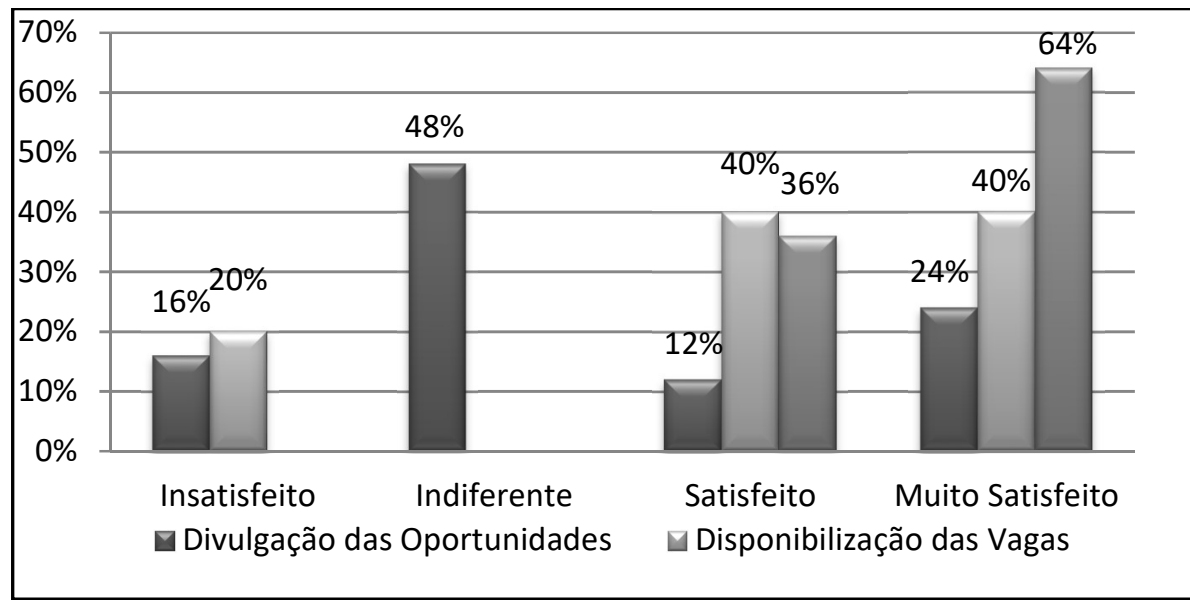

Figura 1: Processo de agregar: nível de satisfação das PCDs. 
A figura 2 demonstra o nível de concordância de gestores e demais colaboradores dos setores onde há PCDs incluídas, se o modo como se dão os processos de agregar pessoas contribuem para a inclusão de PCDs na organização. Nessa perspectiva, a figura 2 foi intitulada 'Processo de agregar: percepção das não PCDs'.

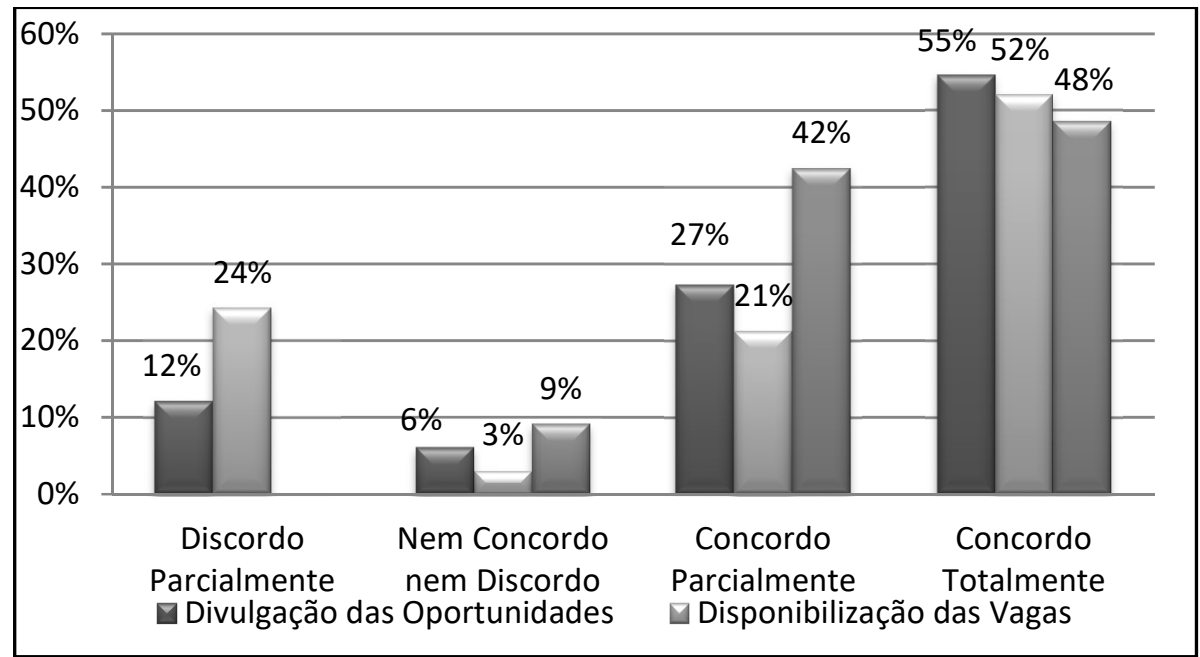

Figura 2: Processo de agregar: percepção das não PCDs.

Verifica-se que em relação à divulgação das oportunidades de trabalho, $48 \%$ das PCDs sentem-se indiferentes, pois entendem que este processo não foi relevante para efetivar sua inclusão na organização. Tal resultado encontra explicação no fato de que a organização não trabalha com anúncios de vagas exclusivamente direcionadas a PCDs, mas mantém em seu website institucional um espaço para que quaisquer candidatos, com ou sem deficiência, possam cadastrar seu currículo profissional e manifestar interesse em trabalhar na cooperativa.

A organização ainda mantém parceria com instituições como FGTAS/Sine - Fundação Gaúcha do Trabalho e Ação Social e INSS - Instituto Nacional do Seguro Social, visando identificar pessoas com deficiência e trabalhadores reabilitados, no sentido de buscar entre estes profissionais aqueles com interesse em se inserir no mercado de trabalho e abrir mão do benefício que recebem da Previdência Social.

Considera-se ainda que, em muitos casos, os próprios colaboradores da organização fazem a indicação de candidatos através de seu network, facilitando assim a provisão de vagas direcionadas às PCDs e dispensando a necessidade de divulgação destas vagas em outros meios. 0 fato de que mais de $80 \%$ das não PCDs concorda parcial ou totalmente que a divulgação das oportunidades contribui para o processo de inclusão, reforça a ideia de que os clientes internos da organização têm acesso às vagas de trabalho para PCDs e auxiliam na comunicação externa destas informações.

Na perspectiva do cumprimento da lei de cotas, a Secretaria de Inspeção do Trabalho sugere que as organizações busquem diversas fontes de recrutamento no intuito de facilitar a captação desta força de trabalho, citando além das agências estaduais de emprego, as escolas, ONGs e demais entidades representativas das pessoas com deficiência.

Bahia (2006) complementa que a ampla divulgação das vagas disponibilizadas a pessoas com deficiência nos meios de comunicação além de promover uma imagem positiva da organização frente a sociedade, ainda encoraja estes sujeitos a buscar seu espaço no mercado de trabalho. Em relação à 
disponibilização das vagas às pessoas com deficiência, verifica-se que $80 \%$ das PCDs consideram-se satisfeitas, enquanto que $73 \%$ das não PCDs concordam total ou parcialmente que este processo ocorre de modo a viabilizar a inclusão, ou seja, que não há discriminação por parte da organização quanto à distribuição de vagas para $P C D$ s e não $P C D$ s.

Nesse contexto, a gerência de RH da organização informa que não há critérios previamente estabelecidos que definam quais vagas serão disponibilizadas às PCDs e que tipo de deficiências podem ser 'aceitas' para cada cargo. Entende-se que dessa forma a organização estará tratando todos os candidatos de forma igualitária e possibilitando que pessoas com deficiência possam ser admitidas em quaisquer setores.

Reforçando esta ideia, Bahia (2006) defende que práticas inclusivas devem permitir que pessoas com deficiência sejam contratadas para quaisquer cargos, independentemente do tipo ou grau de severidade da deficiência, desde que profissionalmente qualificadas e aptas ao cargo. O Ministério do Trabalho, através da Secretaria de Inspeção do Trabalho (2007) ainda conclui que a disponibilização de vagas somente às pessoas com deficiência leves caracteriza-se como ato discriminatório, pois o que deve ser buscado pela organização é a pessoa e não a deficiência.

Referente ao processo de seleção, $100 \%$ das PCDs consideraram-se satisfeitas ou muito satisfeitas. As não PCDs, em quase sua totalidade (91\%) também concordam parcial ou totalmente que os métodos de seleção adotados pela cooperativa promovem a inclusão. A gerência de RH afirma que o processo seletivo de PCDs e não PCDs também segue o mesmo padrão, iniciando com a etapa de triagem de currículos, entrevista com banca (composta pela gerência do setor, psicóloga e outro profissional de RH), dinâmicas de grupo, avaliação de competências e, dependendo do cargo, prova teórica e prática.

Entende-se que, para haver um processo justo, não há distinção entre candidatos com e sem deficiência e que estes participam do mesmo processo seletivo. Eventualmente, dependendo do tipo e grau de deficiência do candidato, são realizadas adaptações (ampliação de provas, presença de tradutor de libras, etc.), visando oferecer ao candidato com deficiência totais condições de participar do processo seletivo em igualdade com os demais candidatos.

A Organização Internacional do Trabalho sugere que a equipe de RH deve adequar as ferramentas e procedimentos do processo de seleção de acordo com as peculiaridades que caracterizam as pessoas com deficiência. Recomenda ainda que, dos candidatos com deficiência não deve ser exigido experiência profissional ou elevado grau de escolaridade, visto que, historicamente, a estes indivíduos não foram viabilizadas oportunidades de formação educacional e profissional. Dessa forma, cabe à organização disponibilizar ferramentas para que o profissional desenvolva internamente as competências e habilidades necessárias.

Em relação ao processo de agregar pessoas, uma pessoa com deficiência geralmente tende a ser vista como menos capaz que as demais. Em virtude disso, cabe ao profissional de RH promover a flexibilização do processo seletivo para facilitar a contratação de PCDs. Entretanto, o ideal é que se mantenha um processo justo e coerente para com todos os candidatos, fazendo prevalecer a cultura da inclusão e não do assistencialismo. Schwarz et al. (2006) finaliza afirmando que, mesmo com a flexibilização dos pré-requisitos 
exigidos, a contratação de candidatos com deficiência é complexa, requerendo alto grau de esforço e investimento por parte das organizações.

\section{Processo de aplicar pessoas}

Bahia (2006) comenta que a preparação do ambiente de trabalho para receber a pessoa com deficiência é extremamente importante para que esta possa desempenhar suas funções de maneira satisfatória. Para analisar a satisfação quanto ao processo de aplicação, as PCDs responderam a perguntas que se referem às práticas de orientação e integração dos novos profissionais na organização, às funções e atividades para as quais são designados e a avaliação de desempenho pela qual são submetidos (figura 3).

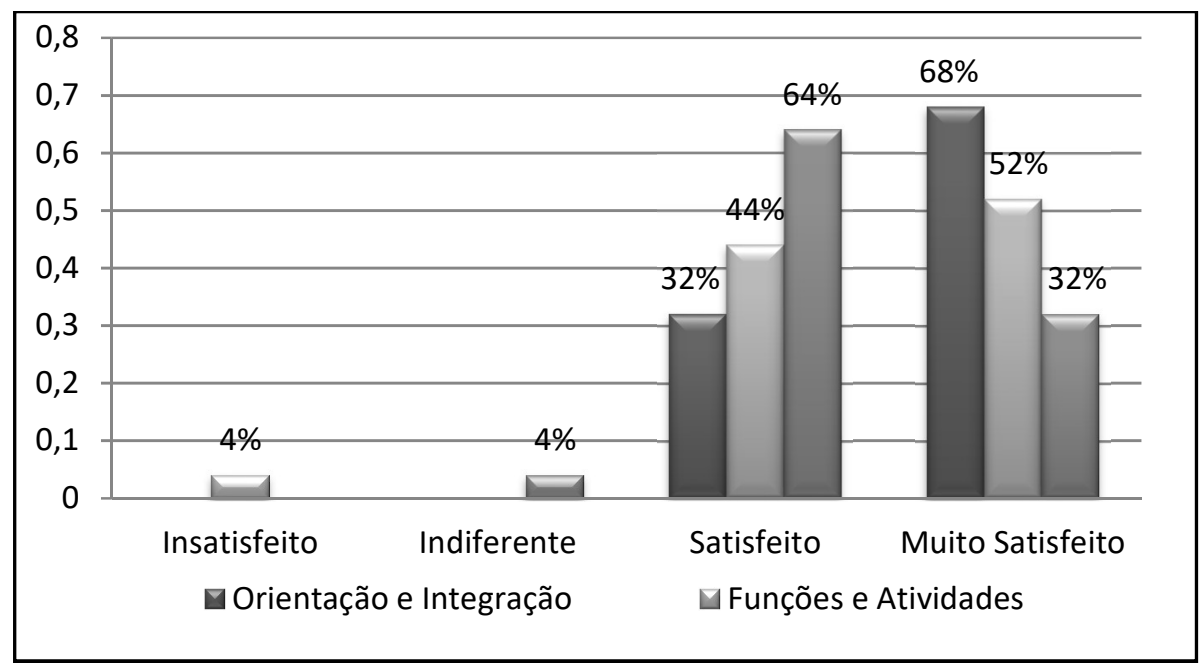

Figura 3: Processo de aplicar: nível de satisfação das PCDs.

A evidenciação da percepção dos gestores de setor e demais colaboradores quanto à contribuição das práticas de aplicação para inclusão de PCDs na organização é apresentada na figura 4. Considerando o processo de orientação e integração dos novos colaboradores na organização, todos os profissionais com deficiência consideraram-se satisfeitos ou muito satisfeitos. De igual forma, os gestores e demais colaboradores responderam concordar parcial ou totalmente com a afirmação de que os processos de orientação e integração corroboram para a efetiva inclusão de PCDs na organização.

Para que a inclusão ocorra de modo efetivo e com responsabilidade, uma vez contratados, os profissionais com deficiência realizam exame médico ocupacional e também são questionados quanto às particularidades de sua(s) deficiência(s), pois é a partir daí que serão desenvolvidas estratégias de integração com os colaboradores e gestores dos grupos de trabalho, visando preparar e sensibilizar as equipes quanto às dificuldades e limitações dos novos colegas. Destaca-se a eficiência dos profissionais de RH da cooperativa que buscam desenvolver empatia com o colega incluído, por exemplo, desafiando a equipe a trabalhar com olhos vendados para receber um deficiente visual e, entender suas limitações. Também oficinas e palestras sobre comunicação através da linguagem de sinais para receber colegas com deficiência auditiva, são alguns exemplos de atividades realizadas para efetiva inclusão. 


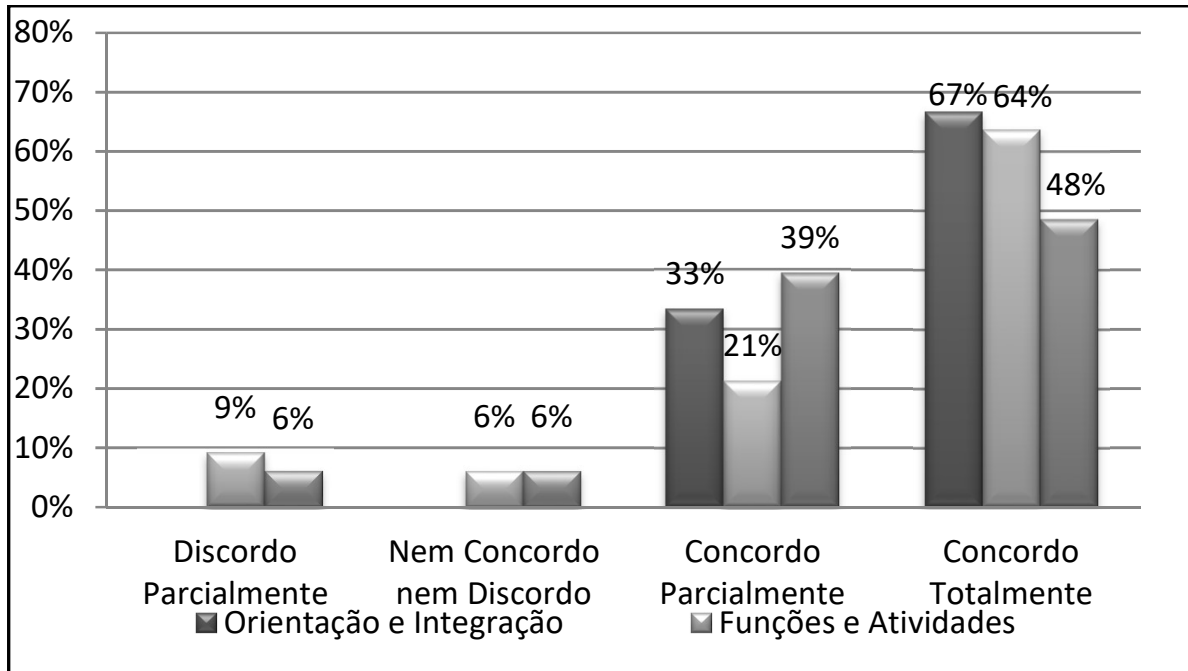

Figura 4: Processo de aplicar: percepção das não PCDs.

Em relação ao trabalho de sensibilização, pode-se concluir que, além de preparar as equipes de trabalho para integrar as PCDs, se torna fundamental no sentido de desmistificar a deficiência e evitar que haja no setor qualquer tipo de estereótipos ou preconceito entre os colegas. Dessa forma, verifica-se que este processo está de acordo com o disposto no decreto no 3.956, de 8 de outubro de 2001, que promulga a Convenção Interamericana para a Eliminação de Todas as Formas de Discriminação contra as Pessoas Portadoras de Deficiência, que objetiva coibir e reprimir qualquer tipo de discriminação e outras atitudes que atentem contra o direito das pessoas a serem iguais permitindo, dessa forma, o respeito e a convivência com as pessoas com deficiência (BRASIL, 2001).

Após a contratação, os profissionais passam pelo processo de orientação, que consiste na apresentação da organização de uma forma geral, no que diz respeito à cultura, comunicação, práticas de saúde, higiene e segurança, regras e procedimentos internos, postura profissional e padrões de conduta recomendados, etc. Além Os novos colaboradores também recebem orientações técnicas relacionadas ao desempenho das atividades específicas relativas à sua função na organização. Há ainda um sistema de apadrinhamento onde um colaborador veterano é responsável por acompanhar e prestar suporte a um novo colega, permitindo assim o estabelecimento de relacionamentos de confiança no ambiente de trabalho.

Para garantir que os objetivos do processo de orientação sejam atingidos, os profissionais de RH desenvolvem um acompanhamento periódico aos colaboradores integrados, principalmente nos três primeiros meses correspondentes ao contrato de experiência. Quando se trata de orientação e integração de PCDs, há um acompanhamento diferenciado e em intervalos de tempo mais curtos, já que consiste num processo que envolve a análise das limitações e capacidades laborais do colaborador, bem como eventuais necessidades de adaptações ambientais. Este acompanhamento periódico das PCDs é abordado nos estudos de Lorentz (2006), que sugere às organizações uma atenção maior no período de adaptação, em virtude de que podem haver necessidades de mudanças físicas, espaciais, psicológicas e/ou laborais não evidenciadas anteriormente.

Em relação às funções e atividades designadas às $P C D$ s, verifica-se que $96 \%$ destes profissionais consideram-se satisfeitos ou muito satisfeitos, enquanto que $85 \%$ das não PCDs concordam parcial ou 
totalmente com a afirmação de que este processo promove a inclusão na organização. Neste quesito, o baixo índice de insatisfação de PCDs também é revelado na mesma proporção no índice de discordância das não PCDs, o que pode significar que num determinado setor, algum profissional com deficiência não se sente incluído a partir das funções e atividades que desempenha, sendo que este descontentamento também pode ser percebido pelos colegas (e talvez pela chefia) de setor.

Em relação às funções distribuídas às PCDs, pode-se afirmar que não há nenhum tipo de exigência legal, cabendo tais decisões exclusivamente à organização. Entretanto, conforme Mendonça (2010), a Recomendação 168 da OIT afirma que manter um profissional com deficiência em setor isolado se caracteriza como uma atitude segregacionista, pois não permite sua integração e desenvolvimento social no emprego. Assim, conforme orienta a Secretaria de Inspeção do Trabalho 'antes de dizer que uma pessoa portadora [sic] de deficiência não tem condições, é preciso dar a ela oportunidade de revelar suas reais potencialidades para desempenhar as funções'.

Segundo as políticas de $\mathrm{RH}$ da organização, não há nenhum tipo de discriminação quanto à distribuição de funções e atividades ou práticas de isolamento de PCDs. Busca-se avaliar a aptidão técnica do colaborador, bem como se o mesmo não é impedido pelo médico do trabalho a executar tais funções. Em casos onde se verifica que o desempenho de determinada tarefa causa algum prejuízo à saúde do colaborador, é realizada a redistribuição de atividades e, conforme se fizer necessário, até mesmo a mudança de cargo. Assim sendo, entende-se que a organização em estudo preocupa-se com a inclusão responsável das PCDs, primando pela saúde destes profissionais e pelo atendimento dos dispositivos legais de inclusão, já que a prática do desmembramento de atividades de forma a adequar o cargo às limitações impostas pelas deficiências é contemplada na Recomendação no 168 da Organização Internacional do Trabalho - OIT (MENDONÇA, 2010).

Nos processos de avaliação de desempenho, verifica-se que $96 \%$ das PCDs estão satisfeitas ou muito satisfeitas, ao passo que quase $90 \%$ dos gestores e demais colaboradores concordam total ou parcialmente com a afirmação de que este processo contribui para promover a inclusão na organização. A avaliação de desempenho se dá por competências e é realizada pelo coordenador de cada setor e por clientes internos, juntamente com o acompanhamento do $\mathrm{RH}$, a partir da descrição de cargos.

Para fins de avaliação, são considerados fatores como as atribuições e competências exigidas do profissional, as atitudes e as participações em treinamentos e formações. A avaliação de desempenho pode gerar quatro resultados diferentes: em adaptação, para quando o profissional não desenvolveu as competências necessárias; domínio parcial, para quando o profissional apresenta desenvolvimento parcial das competências, porém ainda necessita de aprimoramento; domínio total, quando demonstra as competências exigidas para o cargo; e excede, para quando o profissional apresentar as competências mínimas e desenvolver outras competências além do esperado.

Na perspectiva da avaliação de desempenho de PCDs, os gestores de RH recomendam aos coordenadores de cada setor que levem em conta as implicações das limitações impostas pelas deficiências no quesito produtividade. Conforme Stone-Romero et al. (2006, citado por SUZANO et al., 2011), na maioria 
das vezes o desempenho negativo das PCDs é atribuído mais a própria deficiência do que a outros fatores. Os mesmos autores apontam, ainda, que quando um funcionário tem deficiência, os gestores podem ter baixas expectativas sobre seu desempenho, as quais são baseadas na relação entre a deficiência e a capacidade da PCD para atender às expectativas de determinada função. Em contraponto, a própria CLT considera no art. $461, \S 4$, que a produtividade das pessoas com deficiência tende a ser inferior e que seu rendimento não pode ser equiparado ao dos demais trabalhadores (BRASIL, 1972).

Contrariando a ideia de que as práticas de gestão de pessoas para PCDs e não PCDs devem seguir os mesmos padrões, encontra-se na avaliação de desempenho a necessidade da flexibilização dos parâmetros de mensuração de produtividade. Contudo, a recomendação no 158 da OIT argumenta que a avaliação especial não pode ser entendida como discriminatória, uma vez que visa proporcionar igualdade de oportunidades para que as PCDs possam participar dos processos de promoção internos (BRASIL, 2007), porém sem atribuir a tal prática um caráter paternalista ou que porventura se converta em privilégios (BRASIL, 1999).

\section{Processo de recompensar pessoas}

Foi investigado o nível de satisfação das PCDs quanto às políticas de salários e benefícios praticadas pela organização na perspectiva da inclusão. Com base no grau de satisfação das PCDs, afirma-se que $80 \%$ informam estar satisfeitas com os salários e benefícios oferecidos pela organização, enquanto que apenas 16\% mostram-se insatisfeitas em relação a este quesito. Durante a aplicação dos questionários, observou-se que os profissionais que se declararam insatisfeitos em relação à remuneração acreditam que a organização deveria adotar políticas de salários e benefícios diferenciadas, exclusivas para colaboradores com deficiência, visto que em muitos casos estes profissionais necessitam de tratamentos médicos especializados, exames e remédios mais caros que as pessoas ditas como 'normais'.

Dentre os gestores e demais colaboradores, apenas $21 \%$ discordam da afirmação de que a política de recompensas da organização não é inclusiva. Em sua maioria, tanto as PCDs quanto os gestores e demais colaboradores, acredita que os salários e benefícios oferecidos às PCDs devem estar nivelados dentro da proposta de igualdade defendida pela organização, não havendo distinção, por exemplo, na remuneração de profissionais que ocupem o mesmo cargo.

De acordo com o que afirmam os gestores de $\mathrm{RH}$, a política salarial da organização é pautada em princípios de valorização das pessoas, visando promover sentimento de igualdade e justiça entre os colaboradores. Para tanto, oferece a todos os profissionais, além do salário, os seguintes benefícios: valetransporte municipal e intermunicipal, planos de saúde e odontológico (custeio parcial), ticket alimentação, refeitório, auxílio creche, maternidade e paternidade cidadã e ainda convênios e descontos com empresas parceiras de diversos segmentos.

A política salarial adotada pela organização é baseada na avaliação e desenho de cargos, pois a organização acredita que para promover a inclusão deve desenvolver práticas de remuneração de maneira igualitária entre PCDs e não PCDs. No tocante a salários e benefícios, o art. 7o da Constituição Federal, inciso 
XXXI, proíbe qualquer discriminação em desfavor da pessoa com deficiência (BRASIL, 1988). Afirma ainda, que o salário deve ser pago de acordo com o trabalho exercido.

\section{Processo de desenvolver pessoas}

Quando questionadas em relação ao processo de desenvolver pessoas (treinamento, crescimento e aprendizagem), 76\% das PCDs afirmaram estar satisfeitas ou muito satisfeitas e que acreditam que estes fatores contribuem para sua efetiva inclusão na organização. As que se consideram insatisfeitas (16\%), manifestaram o desejo de participar de treinamentos e capacitações específicos que pudessem colaborar para promoção de cargo.

Considerando a percepção dos gestores de setor e demais colaboradores, $67 \%$ concordam parcial ou totalmente com a afirmação de que os processos de treinamento, crescimento e aprendizagem desenvolvidos pela organização permitem a inclusão de PCDs e apenas $3 \%$ discordam totalmente. Dentre estes, há ainda os que elogiam a atuação do setor de RH no sentido de oferecer palestras e treinamentos para sensibilização dos grupos de trabalho, pois dessa forma, além de compartilharem informações sobre as deficiências, provocam nos colaboradores a dissolução de preconceitos e o engajamento para que a inclusão dos colegas com deficiência aconteça da maneira mais natural possível.

\section{Processo de manter pessoas}

No âmbito da inclusão das PCDs, buscou-se identificar a satisfação quanto às práticas de higiene e segurança do trabalho, acessibilidade e relacionamento com colegas e chefia, conforme se pode notar na figura 5, que foi intitulada, graficamente propondo, 'Processo de manter: nível de satisfação das PCDs', no qual foram propostos sob 4 classificações.

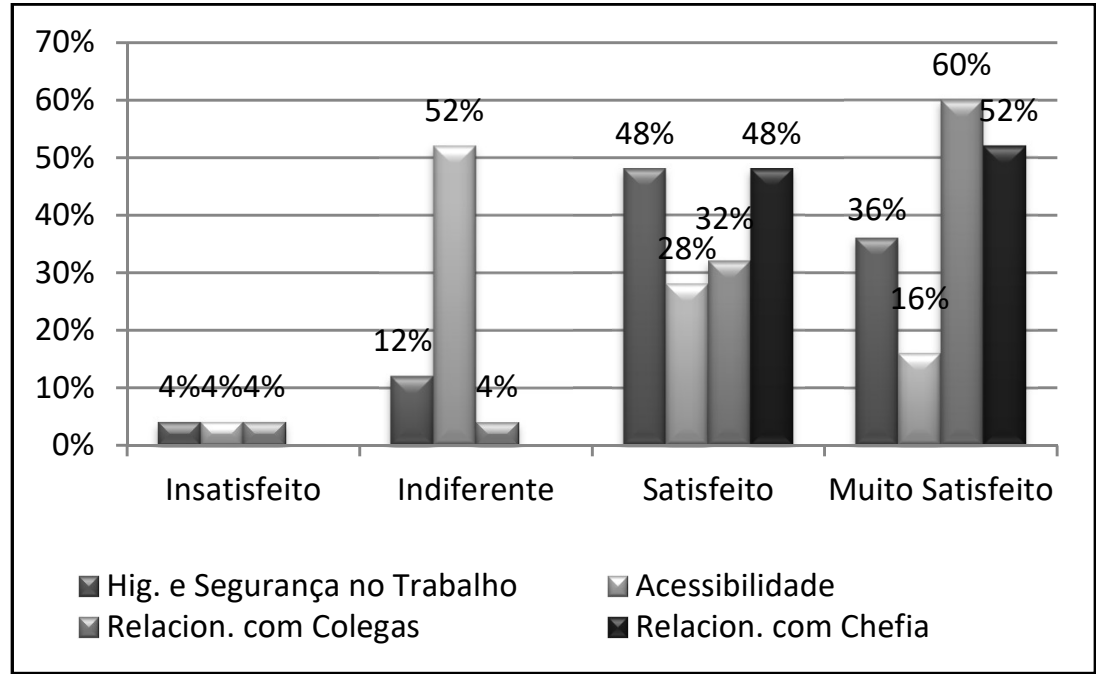

Figura 5: Processo de manter: nível de satisfação das PCDs.

Analisando as práticas de higiene e segurança do trabalho, $84 \%$ consideram-se satisfeitos ou muito satisfeitos. Alguns destes informaram que a organização dispõe de profissionais qualificados que prestam atendimento e acompanhamento contínuo no que se refere aos aspectos físicos do ambiente de trabalho, prezando pela limpeza, ergonomia e práticas de segurança em todos os setores. Os que se consideraram 
insatisfeitos ou indiferentes, não souberam ou não quiseram justificar suas respostas. De forma bastante semelhante, os coordenadores de setor e demais colaboradores apresentaram elevado índice de concordância parcial ou total (94\%) sobre a afirmação de que as práticas de higiene e segurança promovem a inclusão de PCDs na organização (figura 6).

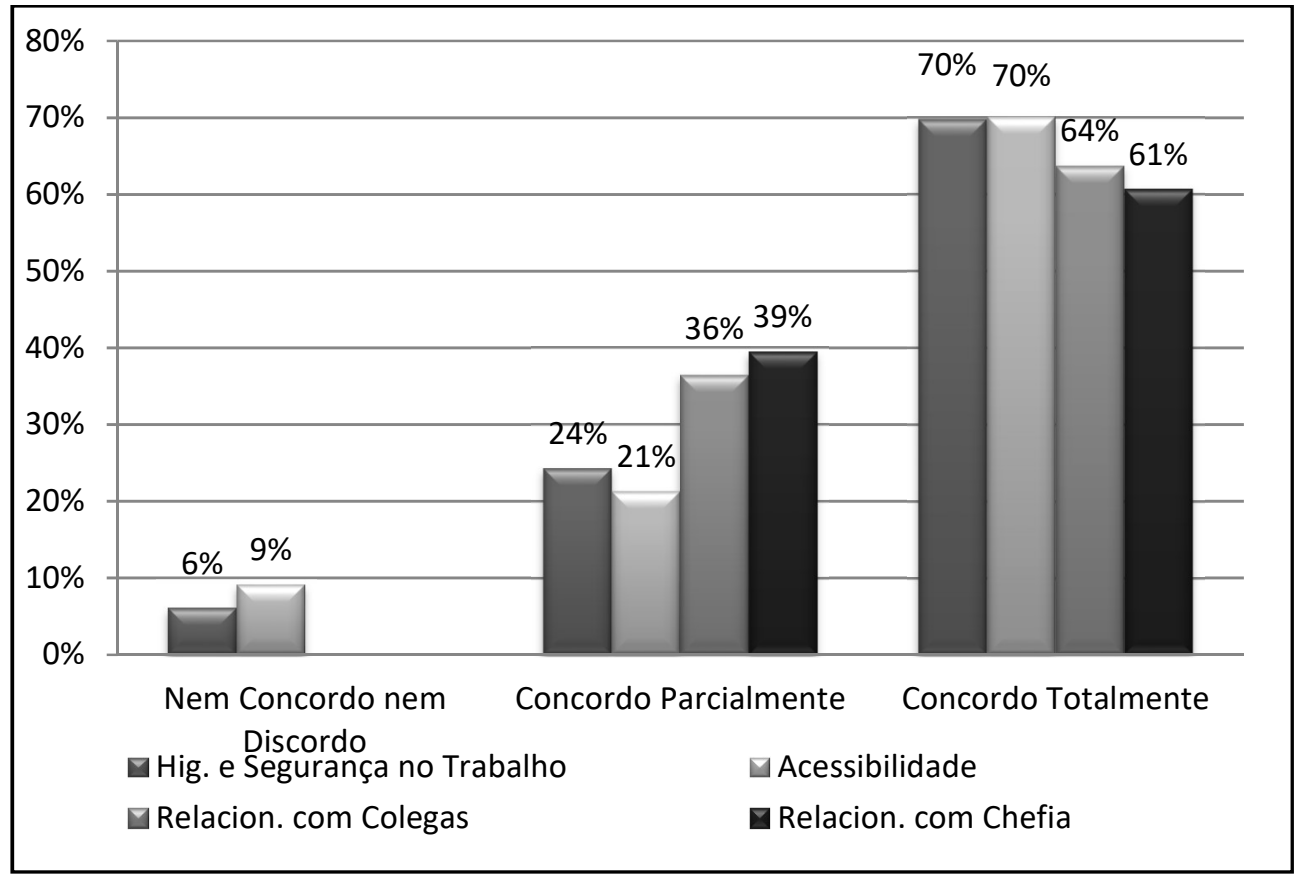

Figura 6: Processo de manter: percepção das não PCDs.

No que se refere à acessibilidade no ambiente de trabalho, 52\% das PCDs declararam-se indiferentes, já que não necessitaram de nenhum tipo de mudanças físicas, espaciais, psicológicas e/ou laborais no ambiente de trabalho. $44 \%$ declararam-se satisfeitos ou muito satisfeitos, considerando-as fundamentais para que o processo de inclusão ocorra de forma plena. A análise das práticas de higiene e segurança e acessibilidade no trabalho também resultaram com altos índices de concordância entre os demais colaboradores e coordenadores de setor, comprovando, assim, a efetividade da inclusão a partir destes processos.

Para garantir a higiene e segurança e acessibilidade no ambiente de trabalho, a organização conta com o trabalho do Sesmt - Serviço Especializado em Engenharia de Segurança e Medicina do Trabalho, que busca prevenir os acidentes e doenças ocupacionais, de modo a proporcionar qualidade de vida ao colaborador, questões ergonômicas, equipamentos e ambiente adequados.

Dentre as principais ações desenvolvidas pelo Sesmt através do Programa Pertencer, destacam-se: identificação e mapeamento de todos os setores onde há colaboradores com deficiência incluídos; avaliação das condições de trabalho oferecidas pela organização; avaliação dos tipos e graus de deficiência dos colaboradores incluídos; ações para eliminar barreiras e promover a acessibilidade ao local de trabalho, além de acesso a banheiros e lavatórios; verificação e aplicação de ajustes ou adaptações de máquinas, equipamentos, estações de trabalho e/ou adequação das tarefas correspondentes ao posto de trabalho; verificação do tempo de jornada de trabalho e dos movimentos repetitivos. 
Em função das particularidades de cada deficiência e o grau de severidade em que ela ocorre nas pessoas, segundo a Secretaria de Inspeção do Trabalho, a palavra do trabalhador deve ser considerada como a principal diretiva na busca dessa melhor adequação das condições e organização do trabalho, pois apenas ele poderá confirmar ou não a adequação de soluções propostas sobre o seu ambiente e organização de trabalho.

No mesmo contexto de manter pessoas na organização, foi investigado se as PCDs se encontram satisfeitas quanto ao relacionamento com colegas e chefia. Constatou-se que todos as PCDs se consideraram satisfeitas com o relacionamento mantido com colegas e chefia, bem como os demais colaboradores e gestores acreditam que tais relacionamentos contribuem para a efetiva inclusão na organização. Deve-se considerar, para este resultado, o trabalho de sensibilização e humanização das equipes, que permite a criação da cultura da inclusão na organização. O relacionamento humano é essencial para manter um ambiente de trabalho com qualidade de vida, pois entende-se que as práticas de inclusão só se tronarão efetivas numa organização onde impere o respeito e a boa convivência com as PCDs.

\section{Práticas de Gestão Pessoas Para Inclusão de PCDs}

Carvalho-Freitas (2007), em suas pesquisas sobre inclusão de pessoas com deficiência no mercado de trabalho, cita as práticas de recursos humanos como fator fundamental de análise em relação a percepção das pessoas, no que tange à adequação dos processos de seleção, treinamento, promoção e transferência, realizadas pela empresa, com vistas a inserir as pessoas com deficiência.

Para uma análise geral da efetividade das práticas de gestão de pessoas para inclusão, fez-se necessário questionar as PCDs quanto ao seu nível de satisfação e concordância em relação à afirmativa de que as práticas de gestão de pessoas promovem a efetiva inclusão de PCDs nas organizações. Apurou-se que $56 \%$ das PCDs consideram-se muito satisfeitas e 44\% satisfeitas em relação às práticas de GP. Entre os gestores e demais colaboradores $61 \%$ concordam totalmente $39 \%$ concordam parcialmente que as práticas de gestão desenvolvidas são inclusivas.

Apesar de alguns respondentes demonstrarem insatisfação e discordância em alguns dos processos de GP, verifica-se aqui, a partir deste resultado, um entendimento da parte dos colaboradores da organização que, de um modo geral, esta é uma organização inclusiva. Constata-se que muitos dos respondentes conhecem a lei de cotas e identificam o grande esforço da cooperativa para não apenas atender todos os requisitos dispostos na legislação, mas sim criar uma cultura inclusiva, valorizando os sujeitos e promovendo a disseminação de valores e princípios igualitários entre seus clientes internos e externos.

Pode-se afirmar que os resultados obtidos a partir da última questão, se dão também em decorrência de que alguns dos respondentes já haviam trabalhado em outras organizações e conheceram uma realidade muito diferente do que encontraram na cooperativa, podendo atribuir sua resposta a um processo de comparação entre estas organizações. Alguns colaboradores se manifestaram no sentido de registrar o acompanhamento diário às PCDs, onde puderam presenciar o quanto a inclusão na organização contribuiu significativamente para o desenvolvimento destas pessoas enquanto sujeitos e cidadãos, 
devolvendo-lhes a dignidade outrora perdida em meio à discriminação e segregação praticadas pela sociedade.

\section{Sugestão de estratégias de GP para as práticas inclusivas de PCDs}

De acordo com Sassaki (1997), para uma empresa ser caracterizada como inclusiva, ela deve se sujeitar a mudanças de paradigmas, de conceitos, de práticas, de valores e de estrutura. Para que as práticas passem de integrativas para inclusivas, tais empresas precisam estar abertas a mudanças e demonstrar flexibilidade nos processos de gestão.

Um dos principais ganhos relativos às práticas inclusivas é o fortalecimento da imagem institucional da organização perante a sociedade. De acordo com o Instituto Ethos (2002), além da motivação ética e da determinação legal, a percepção do consumidor brasileiro quanto à responsabilidade social pode ser um fator estratégico determinante no processo de decisão de consumo.

Nessa perspectiva, sugere-se investimento na comunicação interna e externa, apresentando suas práticas inclusivas à comunidade; buscar a obtenção da ISO 16001, que certifica e reconhece a organização em nível nacional através das práticas voltadas a temas associados à ética, à cidadania, aos direitos humanos, ao desenvolvimento econômico, ao desenvolvimento sustentável e à inclusão social; e como estratégia de comunicação, sugere-se a ampla divulgação do processo seletivo em mídias como rádio, jornal, televisão e redes sociais, podendo ter acesso a um maior número de candidatos PCDs.

Para que possam ser incorporados contingentes maiores de PCDs, a organização pode buscar financiamento junto ao governo federal através do Programa de Apoio a Investimentos Sociais das Empresas - PAIS, onde o BNDES dispõe de aportes financeiros destinados à iniciativas que visam incluir pessoas com deficiência nas organizações, no que tange a obras civis de engenharia, adaptação física de instalações, aquisição de equipamentos e materiais especiais, elementos especiais para facilitar a comunicação e a capacitação de pessoas para o convívio no ambiente de trabalho (LORENTZ, 2006).

Além disso, rodízios periódicos de profissionais entre os setores (na medida do possível) ou então o estabelecimento de vínculos entre as PCDs e as demais equipes de trabalho da organização, já que, conforme relatado pelos gestores os índices de absenteísmo e rotatividade de PCDs é baixo. Diante da obrigatoriedade em manter a cota mínima de $4 \%$ das vagas ocupadas por PCDs, sugere-se à organização adotar uma margem de, pelo menos $6 \%$.

\section{CONSIDERAÇÕES FINAIS}

O objetivo proposto foi realizado analisando a satisfação dos colaboradores com deficiência e a percepção dos colegas de trabalho quanto as práticas de gestão de pessoas, frente a inclusão e as políticas de cotas, em uma Cooperativa de Saúde da região noroeste do estado do Rio Grande do Sul. Evidenciandose que as práticas de gestão de pessoas da organização em estudo promovem a efetiva inclusão de PCDs, pois a maioria dos colaboradores com deficiência estão satisfeitos quanto aos processos e que a maioria dos 
seus colegas também possuem essa percepção, sentindo que a inclusão não é apenas o cumprimento da lei de cotas, na cooperativa em estudo.

Existe o sentimento por parte dos PCDs e seus colegas, de desenvolvimento das pessoas com deficiência enquanto sujeitos e cidadãos, sendo the devolvida a dignidade outrora perdida em meio à discriminação e segregação praticadas pela sociedade.

Uma das limitações para realizar este estudo é a gama de referenciais teóricos incipientes e estudos ainda emergentes que possuem poucos conceitos recorrentes especialmente na literatura brasileira sobre gestão de pessoas e inclusão de PCDs. O que por outro lado permite a sugestão de que se continuem as pesquisas envolvendo tais temas.

Ao longo do desenvolvimento deste estudo, foram identificadas outras dimensões que novos estudos poderiam ser abordadas e contribuir para um melhor entendimento do processo de inclusão de PCDs nas organizações. Uma destas dimensões se refere a pesquisa de clima organizacional em equipes de trabalho onde há PCDs incluídas. Tal estudo torna-se relevante para investigar a relação da inclusão de profissionais com deficiência com os níveis de satisfação, motivação e desempenho de equipes de trabalho, associando ainda à cultura e valores organizacionais.

Buscando um universo além das práticas de gestão de pessoas para a inclusão de PCDs, é possível ainda pesquisar se as organizações desenvolvem a inclusão de maneira estratégica, buscando um diferencial competitivo no mercado. Em se tratando de marketing, também é possível analisar os impactos da inclusão de PCDs no endomarketing e no marketing institucional das organizações. Por fim, ainda há a possibilidade de verificar como ocorre o processo de inclusão em outras organizações do setor privado (indústria e comércio), podendo ainda proceder com análises comparativas em relação ao setor público.

\section{REFERÊNCIAS}

BAHIA, M. S.. Responsabilidade social e diversidade nas organizações: contratando pessoas com deficiência. Rio de Janeiro: Qualitymark, 2006.

BEUREN, I. M.. Como elaborar trabalhos monográficos em contabilidade: teoria e prática. 2 ed. São Paulo: Atlas, 2004.

BRASIL. Constituição Federal de 1988. Brasília: DOU, 1988.

BRASIL. Decreto n.3298 de 20 de dezembro de 1999.

Regulamenta a Lei no7.853, de 24 de outubro de 1989, dispõe sobre a Política Nacional para a Integração da Pessoa Portadora de Deficiência, consolida as normas de proteção, e dá outras providências. Brasília: DOU, 1999.

BRASIL. Decreto n.3956 de 08 de outubro de 2001. Promulga a Convenção Interamericana para a Eliminação de Todas as Formas de Discriminação contra as Pessoas Portadoras de Deficiência. Brasília: DOU, 2001.

BRASIL. Decreto n.6949 de 25 de agosto de 2009. Promulga a Convenção Internacional sobre os Direitos das Pessoas com Deficiência e seu Protocolo Facultativo, assinados em Nova York, em 30 de março de 2007. Brasília: DOU, 2009
BRASIL. Lei n.5764 de 16 de dezembro de 1971. Define a Política Nacional de Cooperativismo, institui o regime jurídico das sociedades cooperativas, e dá outras providências. Brasília: DOU, 1971.

BRASIL. Lei n.5798 de 31 de agosto de 1972. Acrescenta 4응 ao art. 461 da Consolidação das Leis do Trabalho, aprovada pelo Decreto-lei no 5.452, de 1ㅇ de maio de 1943. Brasília: DOU, 1972.

BRASIL. Ministério da Educação. Resolução de 09 de dezembro de 1975: Declaração dos direitos das pessoas deficientes. Brasília: MEC, 1975.

BRASIL. Ministério do Trabalho e Emprego. A inclusão de pessoas com deficiência no mercado de trabalho. 2 ed. Brasília: MTE, 2007.

BRASIL. Ministério do Trabalho e Emprego. Características do emprego formal: Rais 2014. Brasília: MTE 2016.

BRASIL. Secretaria de Direitos Humanos. História do movimento político das pessoas com deficiência no Brasil. Brasília: SDH, 2010. 
BRASIL. Secretaria Especial dos Direitos Humanos. A convenção sobre os direitos das pessoas com deficiência: versão comentada. Brasília: SEDH, 2008.

\section{BÜTTENBENDER, P. L.. Doutrina e educação cooperativa.} Ijuí: Unijuí, 2008.

CARVALHO-FREITAS, M. N.. Inserção e gestão do trabalho de pessoas com deficiência: um estudo de caso. Revista de Administração Contemporânea, Curitiba, v. 13, p.121-138, 2009.

CHIAVENATO, I.. Gestão de pessoas: o novo papel dos recursos humanos nas organizações. 3 ed. Rio de Janeiro: Elsevier, 2010.

DUTRA, J. S.. Competências: conceitos e instrumentos para a gestão de pessoas na empresa moderna. São Paulo: Atlas, 2004.

GIL, A. C.. Como elaborar projetos de pesquisa. 5 ed. São Paulo: Atlas, 2010.

GIL, A. C.. Gestão de pessoas: enfoque nos papéis profissionais. São Paulo: Atlas, 2007.

GIL, A. C.. Métodos e técnicas de pesquisa social. 6 ed. São Paulo: Atlas, 2008.

GUGEL, M. A.. Pessoas com deficiência e o direito ao trabalho. Florianópolis: Obra Jurídica, 2007.

IBGE. Instituto Brasileiro de Geografia e Estatística. Censo demográfico 2010: características gerais da população, religião e pessoas com deficiência. Rio de Janeiro: IBGE, 2010.
LORENTZ, L. N.. A norma da igualdade e o trabalho das pessoas portadoras de deficiência. São Paulo: LTr, 2006.

MARRAS, J. P.. Administração de recursos humanos: do operacional ao estratégico. 12 ed. São Paulo: Futura, 2007.

MENDONÇA, L. E. A.. Lei de cotas: pessoas com deficiência: a visão empresarial. São Paulo: LTr, 2010.

MILKOVICH, G.; BOUDREAU, J. W.. Administração de recursos humanos. São Paulo: Atlas, 2000.

SASSAKI, R. K.. Inclusão: construindo uma sociedade para todos. 7 ed. Rio de Janeiro: WVA, 1997.

SASSAKI, R. K.. Inclusão: o paradigma do século 21. Revista da Educação Especial, Brasília, v.1, n.1, p.19-23, 2005.

SASSAKI, R. K.. Vida Independente: história, movimento, liderança, conceito, filosofia e fundamentos. São Paulo: RNR, 2003.

SCHWARZ, A.; HABER, J.. População com deficiência no Brasil: fatos e percepções. São Paulo: Coleção Febraban de Inclusão Social, 2006.

SILVA, O. M.. A epopeia ignorada: a pessoa deficiente na história do mundo de ontem e de hoje. São Paulo: Cedas, 1987.

SUZANO, J. C. C.. Formas de ver as pessoas com deficiência e avaliação do desempenho no trabalho, por tipo de deficiência: a percepção dos gestores. In: ENCONTRO DA ASSOCIAÇÃO NACIONAL DE PÓS-GRADUAÇÃO E PESQUISA EM ADMINISTRAÇÃO, 35. Anais. Rio de Janeiro: ANPAD, 2011. 